EPJ Web of Conferences 12, 02002 (2011)

DOI: $10.1051 /$ epjconf/20111202002

(C) Owned by the authors, published by EDP Sciences, 2011

\title{
Integrity assessment of grouted posttensioning cables and reinforced concrete of a nuclear containment building
}

\author{
K. Philipose ${ }^{1}$ and B. Shenton ${ }^{2}$ \\ ${ }^{1}$ Atomic Energy of Canada Limited (Retired), Chalk River, Ontario, Canada \\ ${ }^{2}$ AMEC Earth \& Environmental Ltd., Hamilton, Ontario, Canada
}

\begin{abstract}
The Containment Buildings of CANDU Nuclear Generating Stations were designed to house nuclear reactors and process equipment and also to provide confinement of releases from a potential nuclear accident such as a Loss Of Coolant Accident (LOCA). To meet this design requirement, a posttensioning system was designed to induce compressive stresses in the structure to counteract the internal design pressure. The CANDU reactor building at Gentilly-1 (G-1), Quebec, Canada (250 MWe) was built in the early 1970s and is currently in a decommissioned state. The structure at present is under surveillance and monitoring. In the year 2000, a field investigation was conducted as part of a condition assessment and corrosion was detected in some of the grouted post-tension cable strands. However, no further work was done at that time to determine the cause, nature, impact and extent of the corrosion. An investigation of the Gentilly-1 containment building is currently underway to assess the condition of grouted posttensioning cables and reinforced concrete. At two selected locations, concrete and steel reinforcements were removed from the containment building wall to expose horizontal cables. Individual cable strands and reinforcement bars were instrumented and measurements were taken in-situ before removing them for forensic examination and destructive testing to determine the impact of ageing and corrosion. Concrete samples were also removed and tested in a laboratory. The purpose of the field investigation and laboratory testing, using this structure as a test bed, was also to collect material ageing data and to develop potential Nondestructive Examination (NDE) methods to monitor Containment Building Integrity. The paper describes the field work conducted and the test results obtained for concrete, reinforcement and posttensioning cables.
\end{abstract}

\section{INTRODUCTION}

The Concrete Containment Buildings (CCB)s of CANDU Nuclear Power Plants (NPPs) were designed to house nuclear reactors and process equipment and also to provide confinement of releases from a potential nuclear accident such as a Loss of Coolant Accident (LOCA). The base slab, perimeter wall and the upper dome form the containment pressure boundary.

To maintain leak tightness, it was important to minimize cracking of the concrete containment structure. To meet this design requirement, a post-tensioning cable (PT) system was designed to induce sufficient residual compressive stress in the structure while maintaining its structural integrity, under all design loading conditions.

G-1 (250 MWe) is a prototype nuclear power plant (NPP) built in the early 1970s and it is currently in a permanent shutdown state. A general arrangement of the G-1 PT cable system and a typical cross section are shown in Figure 1. As shown in the figure, the base slab is post-tensioned with two layers of cables, the perimeter wall with both vertical and horizontal (circumferential) cables and the dome with one layer of cables, arranged in three directions at $120^{\circ}$ offset.

Corrugated metal ducts, containing PT cables were placed in the formwork during construction before placing concrete, except for the vertical wall cables, where a hole was created during slip forming

This is an Open Access article distributed under the terms of the Creative Commons Attribution-Noncommercial License 3.0, which permits unrestricted use, distribution, and reproduction in any noncommercial medium, provided the original work is properly cited. 


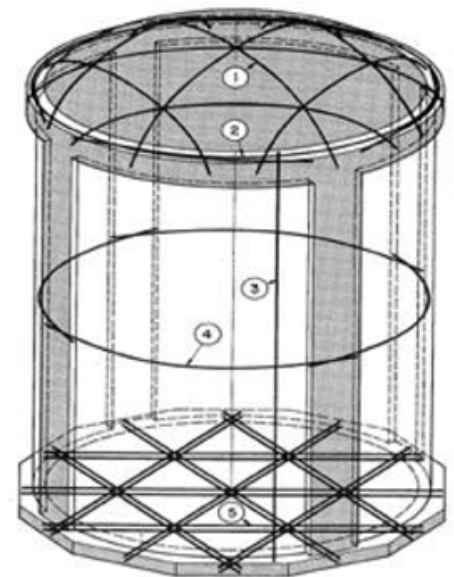

GENERAL ARRANGEMENT

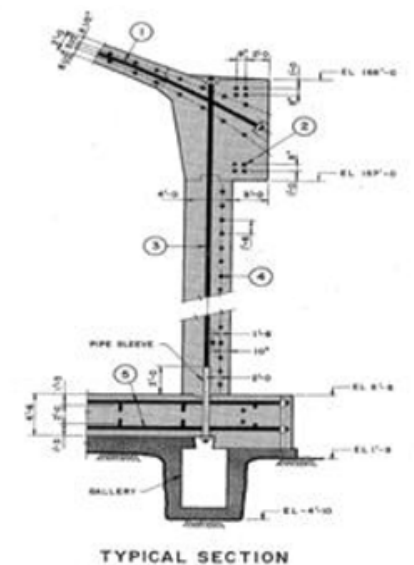

TYPICAL SECTION
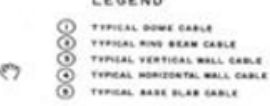

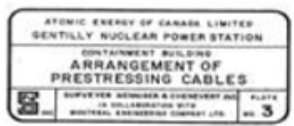

Figure 1. Gentilly-1 NPP post-tensioning cable layout.

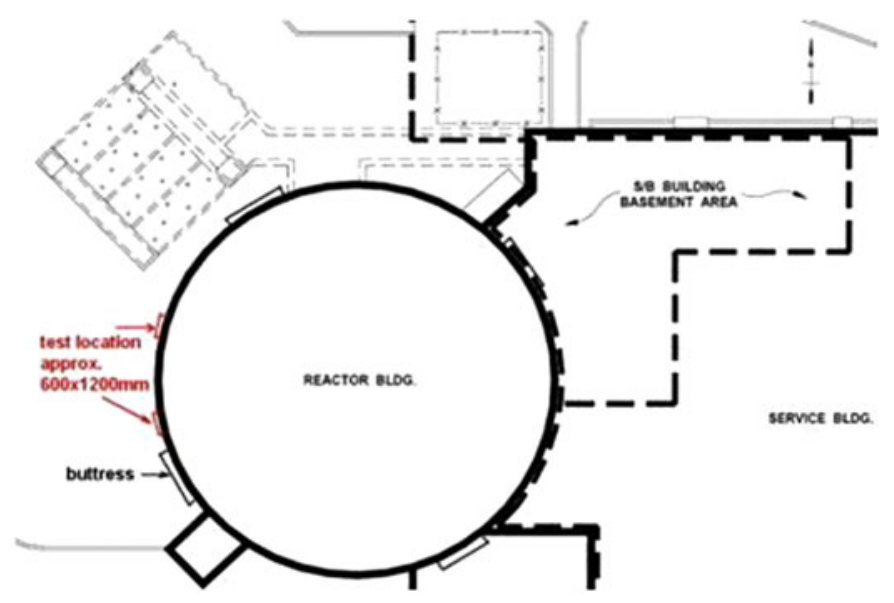

Figure 2. Selected location for field testing.

of the perimeter wall and the cables were threading into the holes at a later date. Once the cables were tensioned, they were grouted in place with a cement based grout to provide corrosion protection for the high strength steel cables. However, the grouting also eliminated the possibility to assess the integrity of cables by conventional "lift off" tests methods. Since G-1 is the oldest Canadian NPP and is under a shutdown state, it was selected for intrusive examination and destructive testing to assess material ageing and to develop potential non-destructive examination methods to monitor integrity of CCB of NPPs. The paper describes the field investigation at the G-1 CCB and some of the observations and findings.

\section{FIELD INVESTIGATION}

The areas selected for field work are shown in Figure 2. As can be seen from the figure, most of the area around the containment building on the East side was covered by service buildings and hence was 


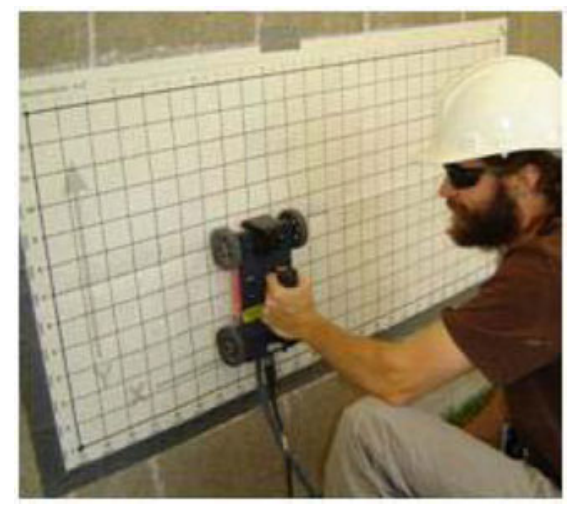

(a)

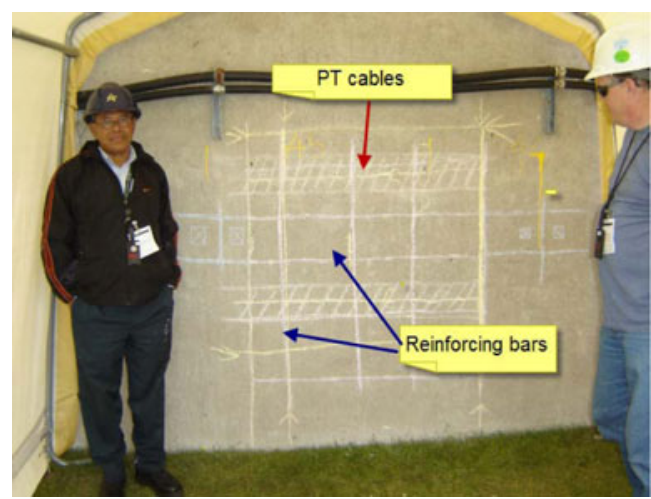

(b)

Figure 3. (a) GPR to locate embedded parts. (b) Embedded parts marked on the wall.

inaccessible at the ground level from outside. Therefore the only area that was available for working at ground level was on the West side.

\section{GROUND PENETRATING RADAR (GPR)}

A Ground Penetrating Radar (GPR) system with three dimensional (3D) imaging capabilities was employed to locate the embedded parts in the wall. A hand held transmitter/receiver was rolled along the vertical and horizontal grid lines to obtain 3D images of embedded steel objects, as shown in Figure 3(a). The GPR system produced accurate locations and depths of embedded reinforcement bars and PT cables. Figure 3(b) shows the location of the embedded parts marked on the wall.

\section{INSTALLATION OF STRESS METERS}

In order to record changes in concrete stresses in the wall due to the removal of concrete, cutting of reinforcements and PT cable strands, four vibrating wire stress meters (VWSM) were installed in 1.5 inch diameter holes core drilled into the concrete on either side of the test areas. The stress meters were installed at a depth of approximately $300 \mathrm{~mm}$, midway between the two horizontal PT cables selected for the investigation.

The stress meters are adapted from the mining industry where they are used to measure stress changes in rock as a result of mining activities. They are a "proving ring" (load cell) design and are wedged into a cored hole (see Figure 4) to measure diametric stress change parallel with the wedge axis. In use, changing stresses in the structure impose changing loads on the gauge body causing the body to deflect, and this deflection is noted as a change in tension and resonant frequency of the vibrating wire element. The square of the vibration frequency is directly proportional to the change in diameter of the gauge and, by calibration, to the change in stress in the structure. The instrument does not determine the absolute stress in the concrete. The stress meter can only determine stress changes.

Figure 4 shows one of the VWSM installation tools (the stress meter is held at the tip of the installation tool) prior to inserting in the wall. The holes in the concrete were washed before inserting the stress meters to make sure that it was clean so that debris would not interfere with the performance of the instruments. 

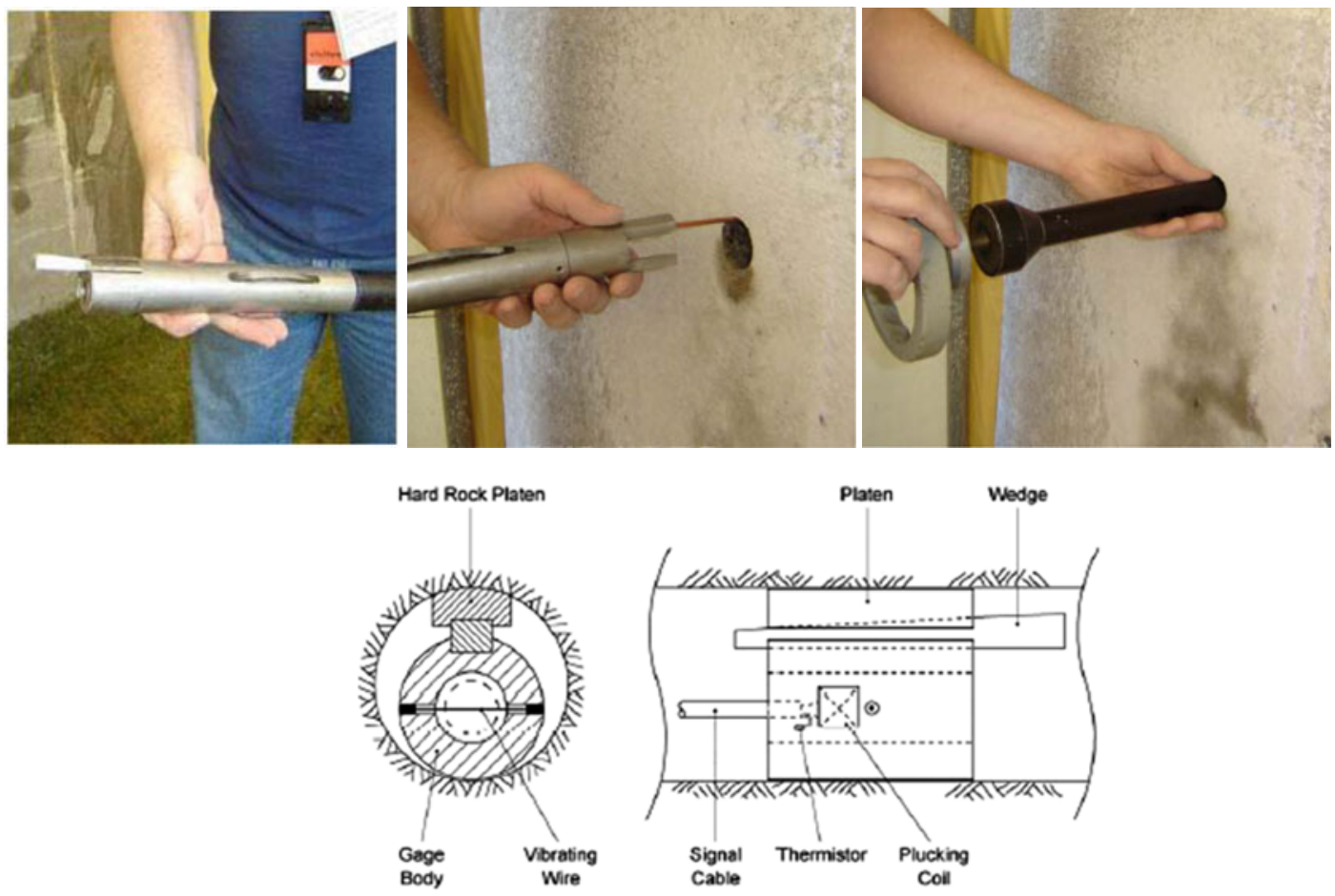

Cross Section

Side View

Figure 4. Pictures showing installation of WVSM in concrete.

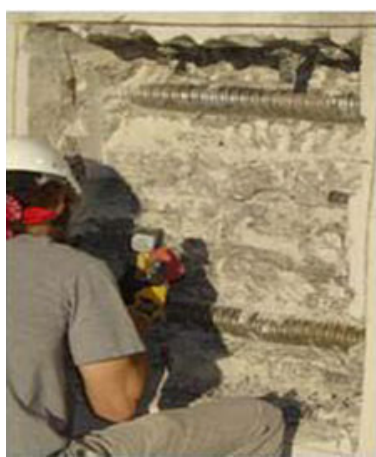

Figure 5. Concrete removed to expose the PT cable ducts.

\section{REMOVAL OF CONCRETE AND REINFORCEMENT BARS}

After the perimeter of the test area was established, the bulk of the concrete was removed using a combination of diamond core drilling, diamond saw cutting, chipping with electrically powered chipping hammers and manual removal by hammer and chisel. To expose the metal duct and reach the PT cables, it was necessary to remove some steel reinforcement bars. Figure 5 shows concrete being removed to expose the PT cables ducts and Figure 6(a) shows reinforcement bars that were removed for testing and 


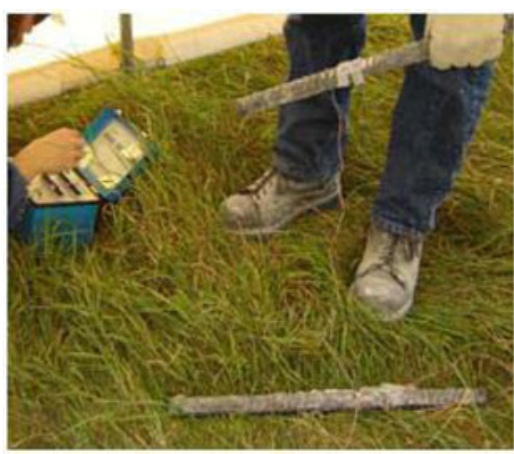

(a)

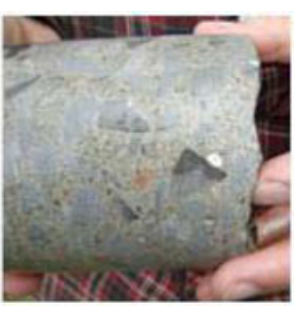

(b)

Figure 6. (a) Reinforcement bars. (b) Concrete core.

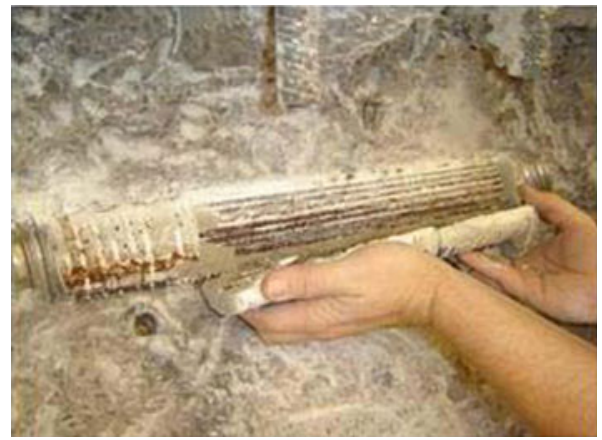

Figure 7. Cement grout being removed to expose cable strands.

Figure 6(b) shows a concrete core taken out of the perimeter wall. Changes in strain on the horizontal steel reinforcement bars were measured during removal from the wall.

\section{REMOVAL OF PT CABLE STRANDS}

The outer surface of the cable ducts were found to be in good condition. The inside surface of the ducts and the cement based grout were stained and contained corrosion products from the corroded PT cables. Figure 7 shows the cement based grout being removed to expose the cable strands.

The cable strands showed corrosion ranging from minor surface staining to widespread flaking and pitting. The severity of the corrosion generally increased towards the lower section in the cable. Several exposed cable strands (total of 32 cable strands) were visually examined; numbered and selected areas were cleaned and polished for installation of bonded foil strain gauges (see Figure 8). Reinforcement bars were also fitted with the strain gauges. Strain gauge readings were taken before and after cutting and removing the PT cable stands and reinforcement bars obtain the residual stresses in the strands and bars.

Cutting of the strands resulted in gaps at the location of the cut, ranging from $10 \mathrm{~mm}$ to $20 \mathrm{~mm}$ in width. The average insitu strain measured in 30 cable strands, that were removed, was approximately 4240 microstrain. Strain gauge readings in showed that stress was transferred from the severed strand to adjacent uncut strands. It was also observed that the grout failed to penetrate in between the strands and did not completely encase all of the strands. 


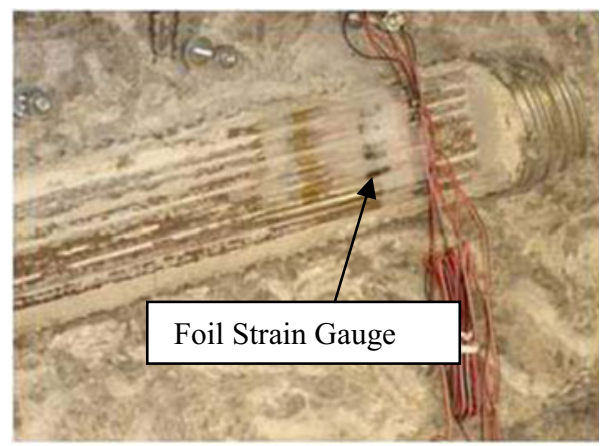

Figure 8. Instrumentation of strands before cutting.

Table 1. Concrete test results.

\begin{tabular}{|c|c|c|c|c|}
\hline Sample Number & $\begin{array}{c}\text { Density } \\
(\mathbf{k g} / \mathbf{m 3})\end{array}$ & $\begin{array}{c}\text { Compressive } \\
\text { Strength } \\
\text { (MPa) }\end{array}$ & $\begin{array}{c}\text { Young's } \\
\text { Modulus } \\
\text { (GPa) }\end{array}$ & Poison's Ratio \\
\hline Area 1A & 2381 & 50.9 & 36.5 & 0.44 \\
\hline Area 1B & 2375 & 50.9 & 23.0 & 0.21 \\
\hline Area 2A & 2458 & 58.6 & 32.2 & 0.26 \\
\hline Area 2B & 2383 & 52.6 & 25.4 & 0.18 \\
\hline
\end{tabular}

\section{LABORATORY TESTING}

\subsection{Concrete}

Concrete samples were tested in the laboratory to determine their unconfined compressive strength, density, hardened air void content (AVS), elastic modulus, chloride ion content and rapid chloride permeability (RCP). Also, petrographic examination of the samples was performed.

Laboratory test results of the concrete samples taken from both test areas are given in Table 1. As shown in the table, concrete compressive strength measured was higher than the nominal design value of $35 \mathrm{MPa}$.

Young's Modulus of concrete is a relationship of stress and strain. The Young's Modulus was obtained by testing the concrete specimen in the laboratory under axial load and measuring the corresponding axial strain.

The Poisons ratio is a function of Young's modulus, which is an axial value, to the Lateral Modulus (a diametric value). The Lateral Modulus was obtained in the laboratory by testing cylindrical concrete specimen and measuring the changes in lateral dimensions in response to the axial loads applied. The Poisons ratios were obtained by dividing the Young's modulus (GPa) by the corresponding lateral modulus $(\mathrm{GPa})$.

The results of the AVS testing (entrained air content $4.3 \%$ to $4.9 \%$ with a spacing factor of 0.165 to 0.172 ), and low values from the (RCP) testing (1172 and 1648 coulombs) show that the concrete properties are currently sufficient to resist the effects of freeze/thaw and chloride ingress to protect the steel reinforcements from corrosion. These properties indicate that the concrete is of good quality.

\subsection{Alkali-Aggregate Reaction, Micro cracking}

Petrographic examination revealed cracking (crack size was not measured but it seems to be micro cracking) of concrete through coarse aggregate and continuing through the concrete mortar, as shown in 


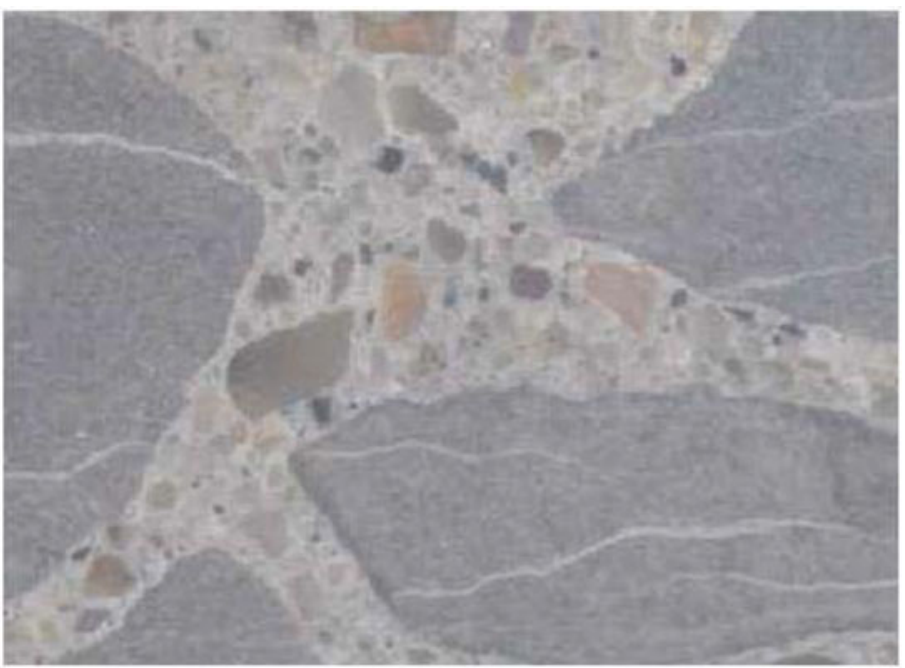

Figure 9. Image showing micro-cracks in concrete.

Figure 9. The crack planes are all oriented parallel to the outer surface of the CCB. The probable cause of the cracking has yet to be confirmed; however, based on knowledge of the geology of aggregate sources in the areas near Gentilly, Quebec, alkali aggregate reaction (AAR), alkali silica reaction (ASR) or alkali carbonate reaction (ACR) are suspected. The material filling the cracks was identified optically under microscopic examination as silica gel, consistent with AlkaliAggregate Reaction (AAR).

The apparent lack of detrimental effects, due to the cracking observed in concrete, on the mechanical and physical properties such as compressive strength and resistance to chloride permeability may be due to the orientation of the cracks. The cracks were perpendicular to the axis of orientation for the RCP and compressive strength tests. No apparent concrete surface cracking on the CCB wall could be due to the confining effect of the PT system. Further research is required to understand the impact of AAR on concrete durability.

\section{POST-TENSIONING CABLES}

Metallurgical examination and destructive tensile testing of cable strands collected from G-1 were performed at AECL laboratories. The tensile testing was done using INSTRON Screwdrive tensile testing machine with wedge type grips.

Figure 10 shows the strand ends after removal from the structure. It can be seen that the strands failed when approximately $50 \%$ of the cross section was severed during removal from the wall. Some necking took place in the specimen while being tested to failure in the laboratory. Figure 11 shows the necking of strands during destructive testing while Figure 12 shows the fracture surface that was typical of very strong steel.

Figure 13 shows the tensile testing machine that was used for the laboratory destructive testing of the cable strands. Three strand specimens were tested and an average yield stress of $1450 \mathrm{MPa}$ and an ultimate tensile stress (UTS) of $1690 \mathrm{MPa}$ were obtained. The stressstrain diagram is shown in Figure 14. The yield and UTS compared well with the design values. 


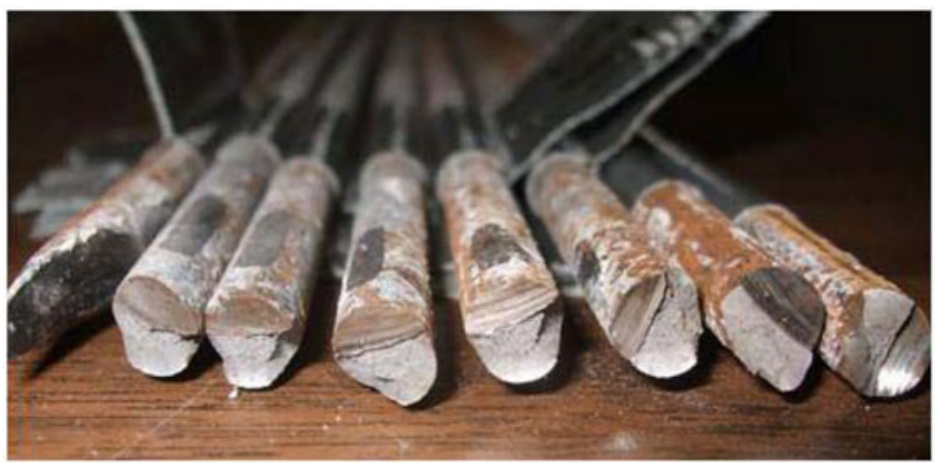

Figure 10. Cable strands cut ends.

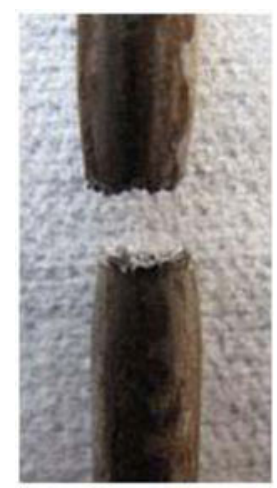

Figure 11. Necking of strand.

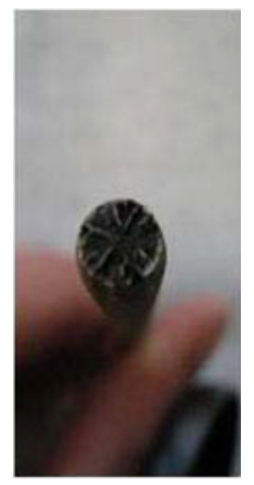

Figure 12. Fracture surface.

\section{STRESS CHANGES IN CONCRETE}

Measurements from the VWSM installed adjacent to the test areas showed that cutting the cable strands resulted in measurable stress changes in the concrete. The stress change and temperature profile for each VWSM were measured at both test areas. This was done by interpreting the data obtained from the 


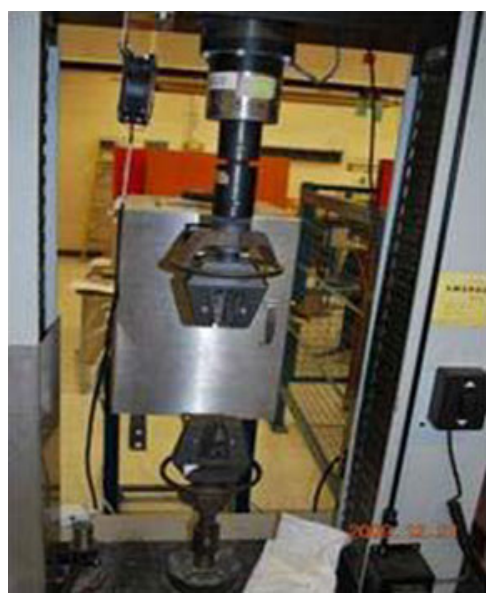

Figure 13. INSTRON screw-drive testing machine.

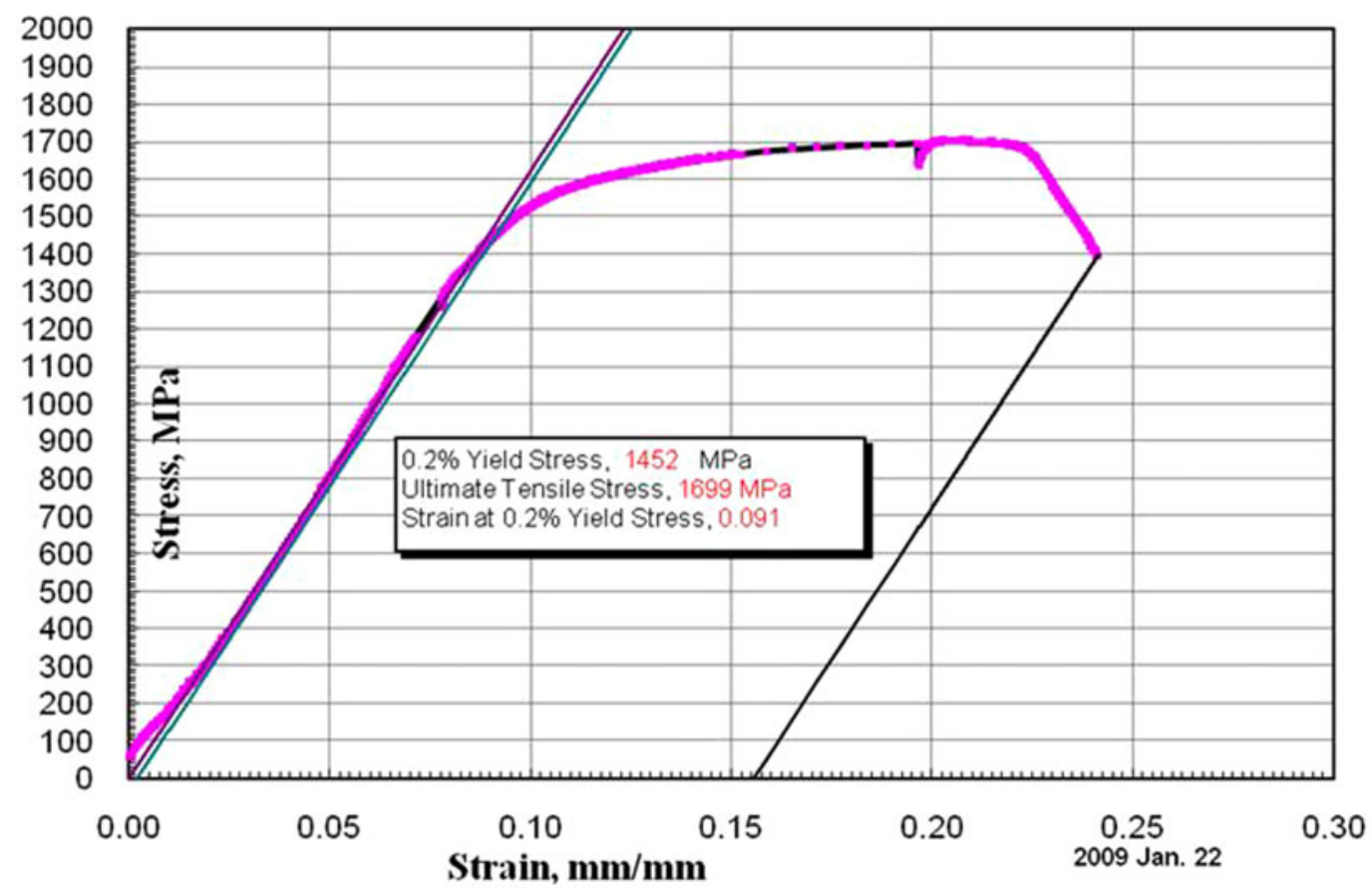

Figure 14. Stress/strain curve for PT strands tested to failure.

VWSM gauges installed in the test holes in concrete before and after the cutting of the cable strands, as mentioned in section 4 .

\section{REINFORCEMENT BARS}

The steel reinforcement bars in the CCB perimeter wall were found to be in very good condition with no evidence of corrosion. Strain measurements on the horizontal reinforcement bars during their removal 
Table 2. Rebar physical properties.

\begin{tabular}{|l|c|c|c|c|c|}
\hline $\begin{array}{l}\text { Rebar } \\
\text { Identification }\end{array}$ & $\begin{array}{c}\text { Yield Strength } \\
\text { (MPa) }\end{array}$ & $\begin{array}{c}\text { Ultimate } \\
\text { Strength } \\
(\mathbf{M P a})\end{array}$ & $\begin{array}{c}\text { Elongation } \\
(\mathbf{\%})\end{array}$ & $\begin{array}{c}\text { Reduction } \\
\text { in Area } \\
(\boldsymbol{\%})\end{array}$ & $\begin{array}{c}\text { Young's } \\
\text { Modulus } \\
(\mathbf{G P a})\end{array}$ \\
\hline 1-top & 505 & 900 & 21 & 50 & 204 \\
\hline 1-bottom & 510 & 875 & 15 & 37 & 208 \\
\hline 2-top & 497 & 865 & 16 & 41 & 214 \\
\hline 2-bottom & 500 & 890 & 16 & 47 & 203 \\
\hline
\end{tabular}

from the test areas showed that the reinforcement bars were under tension prior to being cut. The average stress on the reinforcement bars was approximately $89.6 \mathrm{MPa}$ based on the results of laboratory elastic modulus testing on specimens recovered from the structure.

\section{CONCLUSIONS}

The first phase of the field investigation yielded a wealth of information on the ageing of the containment building wall of the CCB nearing 40 years of age. The second phase of the investigation will include the dome of the CCB.

The concrete and reinforcement bars were found to be in good condition. The concrete ultimate compressive strength obtained by laboratory testing was $40 \%$ higher than the design specification of $35 \mathrm{MPa}$. Concrete suffered micro cracking probably due to alkali aggregate reaction. However, this has not affected the performance of the concrete in the orientation in which the testing was conducted. This could be due to the confining effect of post-tensioning system. Ultimate strength of reinforcement bars ranged between $865 \mathrm{MPa}$ to $900 \mathrm{MPa}$ indicating that they have suffered no apparent adverse ageing effects.

The horizontal post tensioning cable strands in both test areas exhibited a varied range of surface corrosion. In spite of that, the strands appeared to be performing well, still meeting the design specifications in ultimate strength. The corrosion of the strands likely occurred during construction when the horizontal wall cables remained in the ducts for an extended period of time before being tensioned and grouted. It seems that the cement grout has well protected steel cable strands from further degradation.

The in-situ residual strain in most of the cable strands measured was in the range of 4000 to 5000 micro strain. This compared well with the original design value of 4600 micro strain corresponding to the specified design working stress of $141,000 \mathrm{psi}$ at 0.6 of the design ultimate stress of $235,000 \mathrm{psi}$. The following topics will be further investigated in the second phase of the project:

- Investigation of the ageing of the CCB dome,

- The cause and impact of pattern micro-cracks in concrete,

- Reasons for the high in-situ tensile stress in horizontal reinforcement bars,

- Development of NDT technologies to monitor the condition of PT cables.

The funding for the project was provided by the CANDU Owners Group.

The authors acknowledge the help of the following colleagues in facilitating the field work and laboratory testing: Jean Vezina of Laprade (AECL), Andre Michel of Laprade (AECL), Brian Leitch (AECL), and Kellen Shenton (AMEC). 